\title{
Perspective of Innovative Changes in Classroom Teaching from the Satisfaction of Students' classroom Teaching in Colleges and Universities
}

\author{
LIU Jingran \\ College of Political Science and Law, Baicheng Normal University, Baicheng, 137000,China \\ email: jingran70@163.com
}

Keywords: College Students, Satisfaction of Classroom Teaching, Perspective, Classroom Teaching, Innovative Change

\begin{abstract}
At present, college students play skipping lessons and play mobile phones in class. The phenomenon of sleeping is very serious. Collective classroom teaching can not meet the students' interest and learning needs. Under the background of college education reform, teachers must innovate classroom patterns to improve students' satisfaction with classroom teaching activities. On the whole, the main factors that influence college students' classroom teaching satisfaction include the teaching methods adopted by teachers, the selected teaching contents, teachers' teaching attitude, classroom teaching effect, and the cultivation of students' innovative ability. Besides, different disciplines and grades will also affect college students' classroom teaching satisfaction. This paper will see the innovative transformation of classroom teaching from the perspective of College Students' classroom teaching satisfaction, and put forward personal suggestions.
\end{abstract}

\section{Introduction}

Higher education has four major functions, namely cultivating innovative talents, scientific research, culture knowledge, and optimize the social service structure. Among them, the cultivation of innovative talents is the core and foundation, give full play to the function to enhance the value of higher education, to meet the social demand for talent development, promote the socialist society Mr. Qu Zhenyuan has also been pointed out. The construction of higher education basic sign from big to strong change is the talent training enhancing the overall quality of teaching in Colleges and universities in China. At present, there are many "teaching and learning" problem lies in the reform of education and teaching "solid. In short, the phenomenon of students skipping classes and class play mobile phone to sleep, the phenomenon is very serious the university classroom, the satisfaction is low, therefore, it is necessary to analysis the college classroom teaching problems, to enhance the students through innovative teaching methods and contents Class satisfaction [1].

\section{Research and Design of College Students' Satisfaction in Classroom Teaching}

The Problem and Hypothesis of College Students' satisfaction in Classroom Teaching. In view of the present situation of College Students' classroom satisfaction, the following three problems are put forward in this paper:

Question one, whether are college students satisfied with classroom teaching activities?

Question two, what are the factors that affect the satisfaction of college students in classroom teaching?

Question three, how should classroom teaching innovate and reform do to improve students' satisfaction in classroom teaching and to meet the students' learning needs?

Before the investigation of these three problems, this paper makes three assumptions. First, college students' classroom satisfaction is generally low. Second, the main factors affecting college students satisfaction of teaching includes the teaching methods used by teachers, teaching content selection, teaching attitude of teachers, classroom teaching, students' innovation ability. Third, training, subject differences and different grades will also affect college students satisfaction of teaching. 
Respondent. This paper takes undergraduates from different majors in key universities as subjects, including Chinese language and literature, science, engineering, education, history, economics, law, management and medicine. The survey is a total of 572 students, 318 girls and 254 boys. The students majored in Chinese language and literature 22, the percentage was 3.8\%; science majors 75, the percentage was 13.1\%; 209 students of engineering professional education, the percentage was $36.5 \%$; 123 . The percentage of $21.5 \%$ students; two students of the history major, accounting for $0.3 \%$ of the proportion of students of economics; 18, the proportion of $3.1 \%$; 26 students majoring in law, the proportion of 45\%; management students 95 people, accounted for 16.6\%; two medical students, the proportion of 0.3\%. 93 freshman, 243 sophomore, 211 Junior, 25 senior.

The survey questionnaire issued a total of 600, the recovery rate was $95.3 \%$, including 28 invalid questionnaires. There are two kinds of questionnaire, the paper issued and paid online. During the investigation, there are two steps, namely prediction issued and formally issued, by predicting the type issued to understand the effect and reliability of questionnaire modify, improper survey project. After two months, began formally issued, was asked to fill in the questionnaire of students, and give them their due reward.

Questionnaire Project and Structure. The questionnaire items has 32 multiple-choice questions, divided into four parts. The first part is the name for the TA (teaching attitude), consists of 5 multiple-choice questions, namely the teacher prepares a lesson earnestly; teacher very much, positive working attitude; teacher correcting homework seriously, patient counseling students, help students solve learning problems teachers love students; teachers; dignified, elegant. The second part is TC (teaching content),consists of a total of five small problems: whether the content of classroom teaching can be applied in practice; frontier of the relationship between teaching content and knowledge; the amount of information resources and the teaching content is rich; the content of classroom teaching the degree of difficulty. The third part is TM (teaching methods), there are six problems: teachers can according to the different teaching contents by different methods; classroom teaching activity is consistent with the teaching contents; teaching language Is smart or not; whether the teachers pay attention to classroom interaction; teachers can skilled application of information equipment to assist teaching; teachers take individualized approach. The fourth part is TE (teaching effect and students' innovation ability),there are five sub problems: the students can obtain various knowledge, improve professional practice skills; equal learning ability and thinking ability the students effectively improve students; social ability increased; the students through classroom cognitive problems, analyze and solve problems; teachers attach great importance to the cultivation of students' creative thinking, cultivating the spirit of innovation, improve the innovation ability of students. The 32 choice has five options: A represents agree, B represents relatively agree, C represents uncertain, D represents disagree, E represents very disagree. Option A score is 5 points, from A to E decreased 1 points, higher scores represent more students' satisfaction High. Table 1 is the satisfaction score of this survey.

Table 1 The total score of College Students' satisfaction in class.

\begin{tabular}{|c|c|}
\hline Satisfaction Score & Student Recovery Score \\
\hline 5 & 7 \\
\hline 4 & 9 \\
\hline 3 & 80 \\
\hline 2 & 274 \\
\hline 1 & 202 \\
\hline
\end{tabular}

From table 1 we can see that the current college students, the classroom satisfaction is generally low. The main influencing factors of College Students' satisfaction of teaching includes the teaching methods used by teachers, teaching content selection, teaching attitude of teachers, classroom teaching, the cultivation of students' innovation ability, and subject differences and different grades will also affect college students satisfaction of teaching. 


\section{Analysis of Innovative Changes in Classroom Teaching in Colleges and Universities from the Results of the Investigation}

Enriching the Content of Teaching and Improving the Satisfaction of the Students. Teachers must base on the teaching objectives, careful preparation, correct their attitude towards teaching, the use of information technology to collect outstanding teaching resources, according to the student's professional disciplines and personalized learning needs to select teaching content, make classroom teaching more fully to improve the students' satisfaction from the foundation. Secondly, teachers should guide students to get rid of bad habits [2]. Such as class, class play mobile phone, sleeping or complete has nothing to do with the class work (such as writing English homework in the ideological and political class). Moreover, teachers should be collaborative school from the specific teaching objectives and the school running characteristics, combined with the law of development of contemporary college students, understand the student's thoughts and knowledge structure. The teaching content and students' life and learning is closely linked to the re integration of teaching materials, which focuses on contemporary university education and teaching practice to learn the value of the root According to the students' career education programs such as the content, promote the organic combination of Ideological and political quality and professional morality, the business needs of the talents into practice teaching content to political theory course, so as to strengthen students' Ideological and political construction and occupation accomplishment, let the students to the classroom knowledge practice in life and in the future in the work, improve students' innovative practical skills [3]. On the other hand, teachers should break the traditional concept of education, change the innovative content of classroom teaching, the teaching content is not confined to the study of daily behavior constraints, today in the network era, teachers can construct the teaching platform with the Internet technology do the dissemination of scientific and cultural knowledge, negative thoughts to guide students to get rid of the bad network culture and fiction, strengthen their own comprehensive qualities, so that not only It is beneficial to improve students' classroom satisfaction, to innovate classroom teaching in colleges and universities, to promote the reform of higher education and to achieve the goal of teaching in colleges and universities [4].

Reforming the Teaching Methods and Promoting the Construction of Information Teaching in Colleges and Universities. In order to reform the teaching methods, to create a good teaching effect, meet the knowledge needs of students, teachers should assist the school constantly improve the construction of information network platform, a good foundation, strengthen the construction of digital campus, enhance the MOOC hardware technology, the use of micro class platform, QQ group and WeChat group to upload text, image, audio, video and other multimedia courseware network resources, carry out classroom teaching, so that students are not able to this time on campus, place restrictions on online learning, discussion forums, download resources, access to information and interactive teaching. Secondly, colleges and universities should pay attention to promoting the construction of Mu class platform, to maintain the stability of Mu class platform function, help students to complete learning tasks smooth in the process of self-study, avoid the job cannot be submitted because of network signal instability or failure of system. At the same time, teachers can set some attractive The incentive mechanism can refine the index of test link (such as proficiency, experience, grade, etc.), so that we can not only improve students' satisfaction, but also guide students to understand their learning needs in time, develop their sense of innovation and improve their professional practice skills [5].

Improving the System of Curriculum Evaluation. Perfect the construction of classroom teaching quality evaluation index system should do the work of three aspects: first, to determine the quality evaluation index of teachers' classroom teaching according to the teaching quality of school [6]. In second, according to the classroom teaching quality evaluation standards to quantify the classroom teaching quality evaluation index. In general, research quality evaluation index of classroom teaching evaluation system should be two pay attention to the teaching evaluation and curriculum evaluation, classroom teaching evaluation content mainly involves the teaching methods used by teachers in the form of lectures, teaching content, teaching attitude and teaching effect evaluation; curriculum evaluation mainly includes the teaching materials, textbooks, courseware, 
classroom questions, homework, evaluation of teaching the project and the final exam content. Third, all quantitative evaluation index system should be constructed after levels, which can Play the role of index by layer by layer [7].

Secondly, the classroom teaching quality evaluation system is a shared system, an effective interaction step progressive in time. The quality of classroom teaching evaluation system mainly includes the system of student evaluation and teacher evaluation, peer evaluation of self. Among them, the student evaluation system consists of two large groups of students and graduates; peer evaluation related to the peer evaluation between the peer and outside the school; the teachers self assessment should be carried out in strict accordance with the indicators. The quality evaluation system of classroom teaching operation must pay attention to the six aspects of the work, which is good, to establish a quality standard for the important teaching links, do measurement and statistical work, complete the evaluation, feedback. The implementation of the necessary regulation. In addition, the classroom teaching quality evaluation work, ensure that the evaluation results of the objective, fair and helpful to improve the quality of teaching in the classroom [8]. The classroom teaching quality evaluation work should adhere to five principles: first, to guide teachers to improve teaching quality in higher education principle; second, objective, fair, fair, reasonable and scientific principles; third, to ensure that teachers' collective participation, widely collect information principle; fourth, to promote the teaching of theory and Practice teaching principles; fifth. The subjective intention and objective reality and combination principle. Note that, in the collection of the evaluation of classroom teaching quality information, students should be as a source of information, voice and listening to the views of students, to develop more scientific and comprehensive evaluation system, implementation of the evaluation work in many aspects, not only attach importance to the teaching effect of the teachers the teaching content and objective evaluation of teachers' selection, teaching methods and teaching attitude, it can efficiently enhance the overall quality of classroom teaching [9].

In addition, to achieve scientific management of teaching in Colleges and universities to improve the teaching quality is a measure of teaching quality evaluation of higher education science and the use of modern management tools. The application software system designed the evaluation index system, operation mode can be the replacement of innovative network teaching quality evaluation system, and teachers and students through the network platform the exchanges to enhance the teaching efficiency in Colleges and universities.

\section{Conclusion}

In summary, in order to improve college students' classroom satisfaction, teachers must innovate the classroom teaching methods, enrich the teaching content, communicate with students, guide the students to get rid of bad learning habits; the reform of classroom teaching methods, creating good teaching effect, meet the knowledge needs of students. Teachers should help our school constantly improve the network platform, build a good information foundation, promote the construction of digital campus, construct a perfect classroom teaching quality evaluation system, and innovate the teaching mechanism in colleges and universities according to the students' satisfaction.

\section{References}

[1] LI Yongle, GONG Jianxia. The analysis of College Students' individual characteristics and the behavior of skipping classes - Based on the survey results of 756 College Students[J]. Heilongjiang Researches on Higher Education, 2016(94)

[2] GE Xiangyang, DENG Hui. The "low head" in the classroom, how to lift the head?[N]. Guang Ming Daily, 2014(05)

[3] DENG Hui. The reform of the system can not be replaced by the reform of the system mechanism[N]. Guang Ming Daily,2015(11) 
[4] XIONG Junhua, MA Dali. Multiple group analysis on the influencing factors of undergraduate teaching satisfaction[J]. Education Science, 2013(05)

[5] WANG Yunwu, ZHU Mingyue. How to change the way of learning: standards and paths[J]. Modern Distance Education Research, 2015(27)

[6] ZHANG Bei, LIN Jiabao. Empirical Analysis on the influencing factors of university teaching satisfaction--Based on the perspective of students' expectations and students' perceived quality[J]. Fudan Education Forum, 2014(04)

[7] LIU Jiliang, WANG Hongxi. "MOOC" to the reform of University Teaching: value and limit[J]. Educational Research, 2015(27)

[8] WAN Shigui, ZHENG Yanlin. The value and teaching of classroom data visualization[J]. Modern Distance Education Research, 2016(05)

[9] MA Xiaohong. Structural equation model of teaching satisfaction in Colleges and Universities [J]. Statistics \& Decision, 2012(20) 